\title{
Review Article \\ Guiding Inspiratory Flow: Development of the In-Check DIAL G16, a Tool for Improving Inhaler Technique
}

\author{
Mark Jeremy Sanders \\ Clement Clarke International Limited, Edinburgh Way, Harlow, Essex CM20 2TT, UK \\ Correspondence should be addressed to Mark Jeremy Sanders; msanders@clement-clarke.com
}

Received 4 August 2017; Accepted 11 October 2017; Published 16 November 2017

Academic Editor: Roberto Walter Dal Negro

Copyright (C) 2017 Mark Jeremy Sanders. This is an open access article distributed under the Creative Commons Attribution License, which permits unrestricted use, distribution, and reproduction in any medium, provided the original work is properly cited.

Portable inhalers are divisible into those that deliver medication by patient triggering (pMDIs: a gentle slow inhalation) and those that use the patient's inspiratory effort as the force for deaggregation and delivery (DPIs: a stronger deeper inspiratory effort). Patient confusion and poor technique are commonplace. The use of training tools has become standard practice, and unique amongst these is an inspiratory flow meter (In-Check) which is able to simulate the resistance characteristics of different inhalers and, thereby, guide the patient to the correct effort. In-Check's origins lie in the 1960s peak expiratory flow meters, the development of the MiniWright peak flow meter, and inspiratory flow assessment via the nose during the 1970s-1980s. The current device (In-Check DIAL G16) is the third iteration of the original 1998 training tool, with detailed and ongoing assessments of all common inhaler resistances (including combination and breath-actuated inhaler types) summarised into resistance ranges that are preset within the device. The device works by interpolating one of six ranges with the inspiratory effort. Use of the tool has been shown to be contributory to significant improvements in asthma care and control, and it is being advocated for assessment and training in irreversible lung disease.

\section{Introduction}

Portable (i.e., pocket-able) inhalers can be divided into those that deliver the medication by patient triggering (e.g., pressurised metered dose devices, pMDIs) and those that use the patient's own inspiratory effort as a force for deaggregation and delivery (e.g., dry powder inhaler devices, DPIs). Each of these two groups requires a different inspiratory effort: pMDIs require a gentle slow inhalation and DPIs require a stronger deeper effort [1]. Patients are known to confuse the techniques when prescribed both types of devices [2].

The importance of inspiratory flow as an influencer of successful inhaler technique is highlighted in the European Respiratory Society/International Society for Aerosols in Medicine (ERS/ISAM) task force document [3]. The closing summary sentences read (this author's emphases): "healthcare providers should ensure that their patients can and will use these devices correctly. This requires that the clinician: is aware of the devices that are currently available to deliver the prescribed drugs; knows the various techniques that are appropriate for each device; is able to evaluate the patient's inhalation technique to be sure they are using the devices properly; and ensures that the inhalation method is appropriate for each patient."

The ERS/ISAM recommendations task the clinician with a series of demanding actions beyond diagnosis and prescription. One of the main consequences, however, of failing to achieve these is poor inhaler technique that delivers not the correct dose of medication but poor asthma control [1]. Such is the complexity and variety of modern inhaler therapies that train-the-trainer workshops and the use of specially designed training tools have become commonplace. The device tools available include placebo inhalers, replica inhalers with inspiratory flow whistles, flow whistle inhaler add-ons, simulators, electronic airflow detectors, and-uniquely-an inspiratory flow meter which is able to simulate the resistance characteristics of different inhalers.

The importance of inhaler technique training is highlighted in the Global Initiative for Asthma guidance [4] and in national asthma guidance [5-8]. Training is usually provided by medical or pharmacy staff but is generally provided in a punctuated fashion with the need for frequent retraining [9]. 


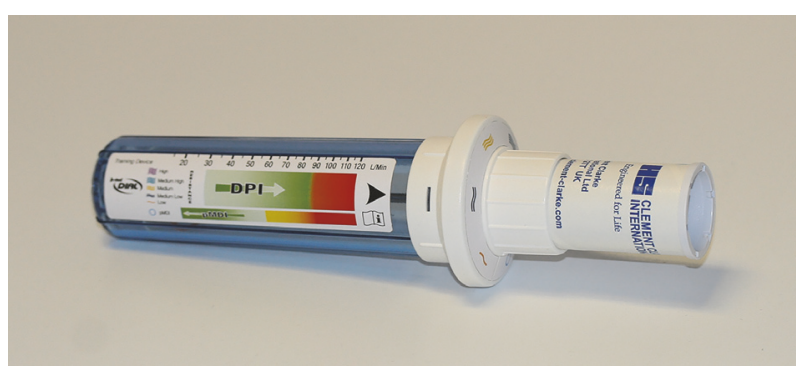

Figure 1: In-Check DIAL G16 (Clement Clarke International Limited). In-Check DIAL G16 is a multipatient clinic/pharmacy device using disposable, single-patient mouthpieces and is used for assessing the inspiratory effort of a patient inhaling through a selected inhaler. The DIAL can be set to resemble the resistance of the inhaler, and the appropriate inhalation-slow and gentle for pMDI and fast and strong for DPI-can be coached. See online animation: https:// www.youtube.com/watch?v=bGCfCGw9 h24.

Some training tools permit ongoing use outside the clinic and facilitate greater training continuity [10]. In addition to inhaler competency training it is important that patient education covers adherence but, allowing for the retraining element, consultation time available for education may be compromised. It is important that competency assessment and training tools align with educational messages.

This article focuses on the history and development of the unique clinic/pharmacy based inspiratory flow meter training device (In-Check DIAL G16, Clement Clarke International Limited).

\section{In-Check DIAL G16}

The In-Check DIAL G16 device is a specialised inspiratory peak flow meter (Figure 1). In many ways it resembles the functioning of a regular peak expiratory flow (PEF) meter. The inspiratory device, however, originates from work in the 1960s [11] using an adaptation of the original large, heavy Wright peak (expiratory) flow meter to determine peak inspiratory flow (PIF) and was used to assess response to bronchodilator therapy in chronic airways obstruction. The now-familiar tubular, "miniature" version was commercialised in the late 1970s following a decade of developmental research [12]. This work led to a special version of the "MiniWright" being developed for peak nasal inspiratory flow measurement and named after the allergist Youlten [13]. A similar adaptation was used by Depledge [14] to investigate the utility of a PEF/PIF ratio in assessing bronchodilator effectiveness.

A Clement Clarke product improvement programme in the 1990s produced the basic In-Check mechanism: a coaching tool to train patients to make an inspiratory flow effort consistent with the requirements of their specific inhaler device(s) [15]. This device was refined in the late 1990s to create the In-Check DIAL $[16,17]$, and has now evolved-particularly as a result of the availability of today's novel inhalers-to its present form as the In-Check DIAL G16 [18], with a measurement range of $15-120 \mathrm{~L} / \mathrm{min}( \pm 10 \mathrm{~L} / \mathrm{min})$.
A further, newer development is the In-Check $\mathrm{M}$, developed from the In-Check DIAL, specific to pMDI use and simulating this inhaler format only.

Throughout the development of the In-Check DIAL products, Clement Clarke amassed a large database of resistance profiles of different inhalers. The basic methodology of resistance profiling was initially described by Clark and Hollingworth [19] and that methodology has been widely adopted by industry when describing device resistance. By conducting all of the measurements on the same calibrated equipment under identical conditions, a relative comparison and classification of inhaler devices by their resistance profile can be assembled. While there are international standards for peak expiratory flow meters [20] there are none for peak inspiratory flow measurement. Clement Clarke, as the sole manufacturer of inspiratory flow meters, has developed the de facto standard.

Early versions of In-Check DIAL identified optimal flow rates for the individually represented inhalers by the inclusion of a restrictive adapter in the dial but a series of developments shifted the emphasis toward the clinically effective range. Optimal flow rates are mainly justified on in vitro delivery data that do not always reflect the dose response behaviour of the drug in vivo [21]. In addition, such was the increase in the number and type of available inhaler devices [22]; there was a clear need to group together inhalers by ranges of device resistance. A summary of these development changes is given in Table 1.

Many inhaler devices are now available with a number of formulation choices, and each of the formulations can have subtle differences in delivery characteristics [30]. Similarly, combination inhaler use is increasing and in some instances the optimal delivery condition for one component may be different to that of another component [31]. Likewise, breathactuated and flow rate triggered devices may have two flow rate characteristics: the first being the effort required to actuate the triggering mechanism and the second the flow rate required to aerosolise and deliver the drug(s) effectively. Breath-actuation flow rate is device-engineered, and trigger rates tend to be set early in the inspiration and relatively low (e.g., pMDI Easi-Breathe $20 \mathrm{~L} / \mathrm{min}$, pMDI Autohaler $30 \mathrm{~L} / \mathrm{min}$, and DPI Nexthaler $35 \mathrm{~L} / \mathrm{min}$ [32]): the implication being that, for deaggregation and aerosolisation of dry powders, the effectiveness of the inspiratory manoeuvre overall may be related to a subsequent higher flow rate and/or acceleration of flow [32-34].

The next stage of product development became, therefore, one of determining how many ranges and the definition of the ranges. Clement Clarke approached this through a consultative process with academic and industry members and the consideration of published reference sources (Table 2).

Various resistance classifications of DPIs have been proposed, including simple 3-point (low, medium, and high) [35] and 4-point definitions (low, medium, medium/high, and high) [3]. The mathematical determinations conducted by Clement Clarke revealed, however, that a broader schema of a single representation of pMDIs, including the specialised soft mist inhaler Respimat [36] and five representations of DPI device resistance (low, medium-low, medium, medium-high, 
TABLE 1: Timeframe and scope of In-Check DIAL development.

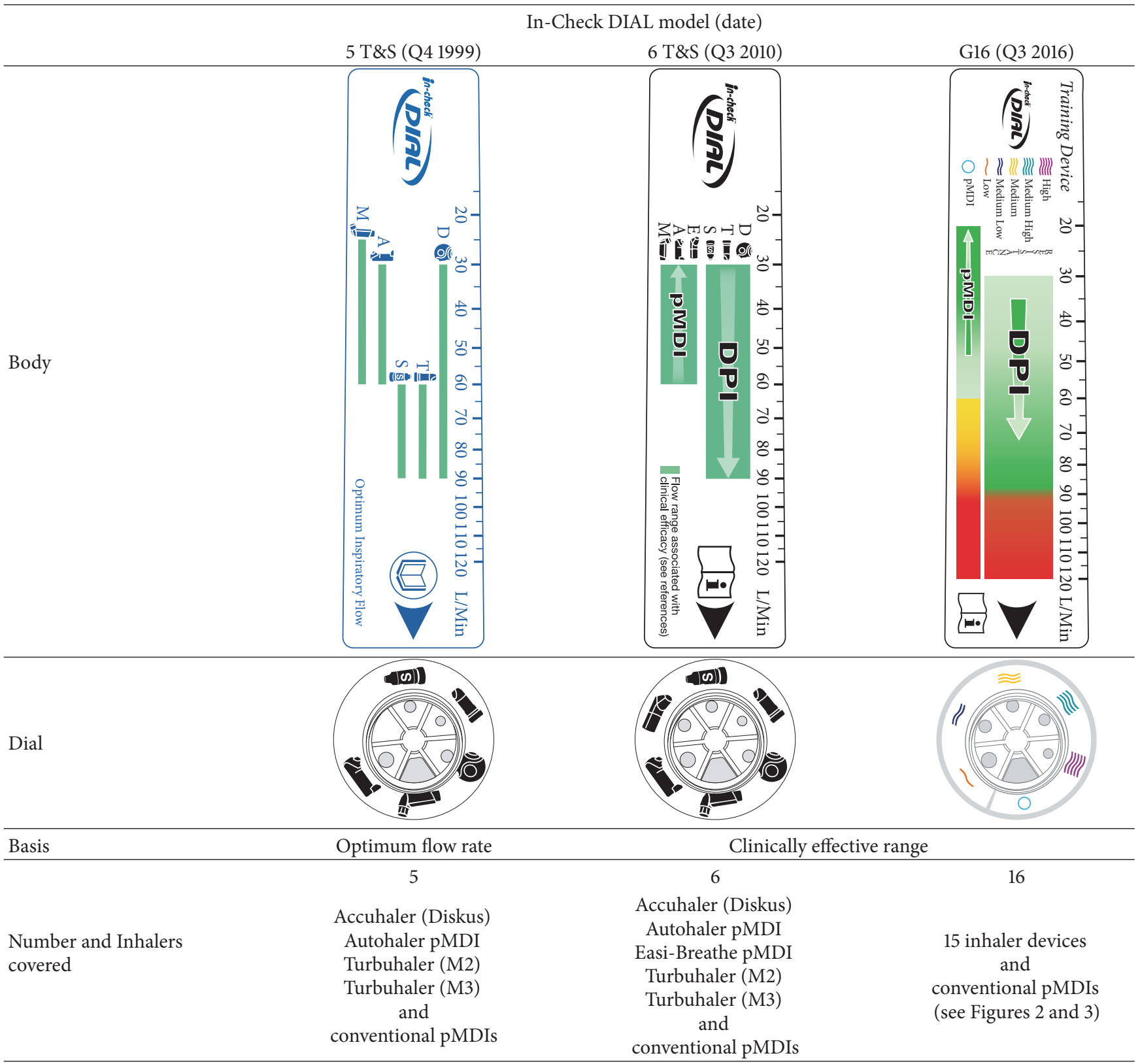

and high), was appropriate (Figure 2). The output of the calculations was compared with published data and despite the determination of published values under frequently noncomparable experimental conditions, there was a good degree of overall conformity. A confounding element is that certain devices have resistance variants (e.g., Turbuhaler M2 and M3) [29]: in some countries and for some of the product range, the original Turbuhaler (often identified as M2) has been replaced with the new Turbuhaler (identified as M3 or the trade name Flexhaler). The newer device has an improved design, permitting actuation quantities of $200 \mu \mathrm{g}$ budesonide and 6 and $12 \mu \mathrm{g}$ formoterol to be replaced by equivalents of $180,4.5$, and $9 \mu \mathrm{g}$, respectively, based on the amount of medication that actually leaves the mouthpiece. Also, when generic formulations are made available in existing inhaler platforms, engineering changes are introduced to ensure comparability with the brand-originator (e.g., to the Easyhaler DPI delivering either a single or combination formulation). This will require great clarity for those referencing inhaler resistances in the future.

The In-Check DIAL G16 resistance profile data are therefore based on fully comparable in-house measurements made under standard conditions by Clement Clarke scientists. For combination inhalers the G16 provides the flow rate ranges which, from published clinical experience, demonstrate efficacy and for breath-actuated devices, to trigger their function. Detailed resistance profile data and relative representations are shared with device originators (Figure 3). 
TABLE 2: Example third party dry powder inhaler resistance measures $\left(\mathrm{kPa}^{1 / 2} / \mathrm{L} \cdot \mathrm{min}^{-1}\right)$.

\begin{tabular}{|c|c|c|c|c|c|c|c|}
\hline \multirow[t]{2}{*}{ DPI device } & \multicolumn{6}{|c|}{$\begin{array}{c}\text { Inhaler resistance measures }\left(\mathrm{kPa}^{1 / 2} / \mathrm{L} \cdot \mathrm{min}^{-1}\right) \\
\text { [Ref. number] }\end{array}$} & \multirow[b]{2}{*}{ [29] } \\
\hline & {$[23]$} & {$[24]^{*}$} & {$[25]$} & {$[26]$} & {$[27]$} & {$[28]^{9}$} & \\
\hline Breezhaler (Neohaler) & 0.02 & 0.0197 & & & & 0.019 & 0.017 \\
\hline Clickhaler & & & & 0.0394 & & & \\
\hline Diskhaler & & & & & 0.032 & & \\
\hline Diskus (Accuhaler) & & 0.0275 & & 0.0249 & 0.034 & 0.026 & 0.027 \\
\hline Ellipta & & 0.0275 & & & & & 0.027 \\
\hline Easyhaler & & & & 0.0424 & & 0.037 & 0.050 \\
\hline $\begin{array}{l}\text { Genuair (Pressair) } \\
\text { [Novoliser] }\end{array}$ & 0.031 & & & & {$[0.028]$} & 0.029 & 0.031 \\
\hline HandiHaler & & 0.0510 & & & & 0.05 & 0.058 \\
\hline Nexthaler & 0.036 & & & & 0.042 & 0.033 & 0.036 \\
\hline Spiromax (Respiclick) & & & 0.0313 & & & & \\
\hline Turbuhaler Pulmicort & & 0.0382 & & 0.0337 & 0.043 & 0.039 & 0.039 \\
\hline $\begin{array}{l}\text { Turbuhaler Symbicort } \\
\text { (Flexhaler) }\end{array}$ & & & 0.0355 & & & 0.033 & 0.035 \\
\hline Twisthaler & & & & & & & 0.044 \\
\hline
\end{tabular}

Note. Resistances determined by one source may differ from another ( $*$ converted from $\mathrm{cm} \mathrm{H}_{2} \mathrm{O}^{1 / 2} / \mathrm{L} \cdot \mathrm{min}^{-1}$, determined from Figure 2 in [28]).

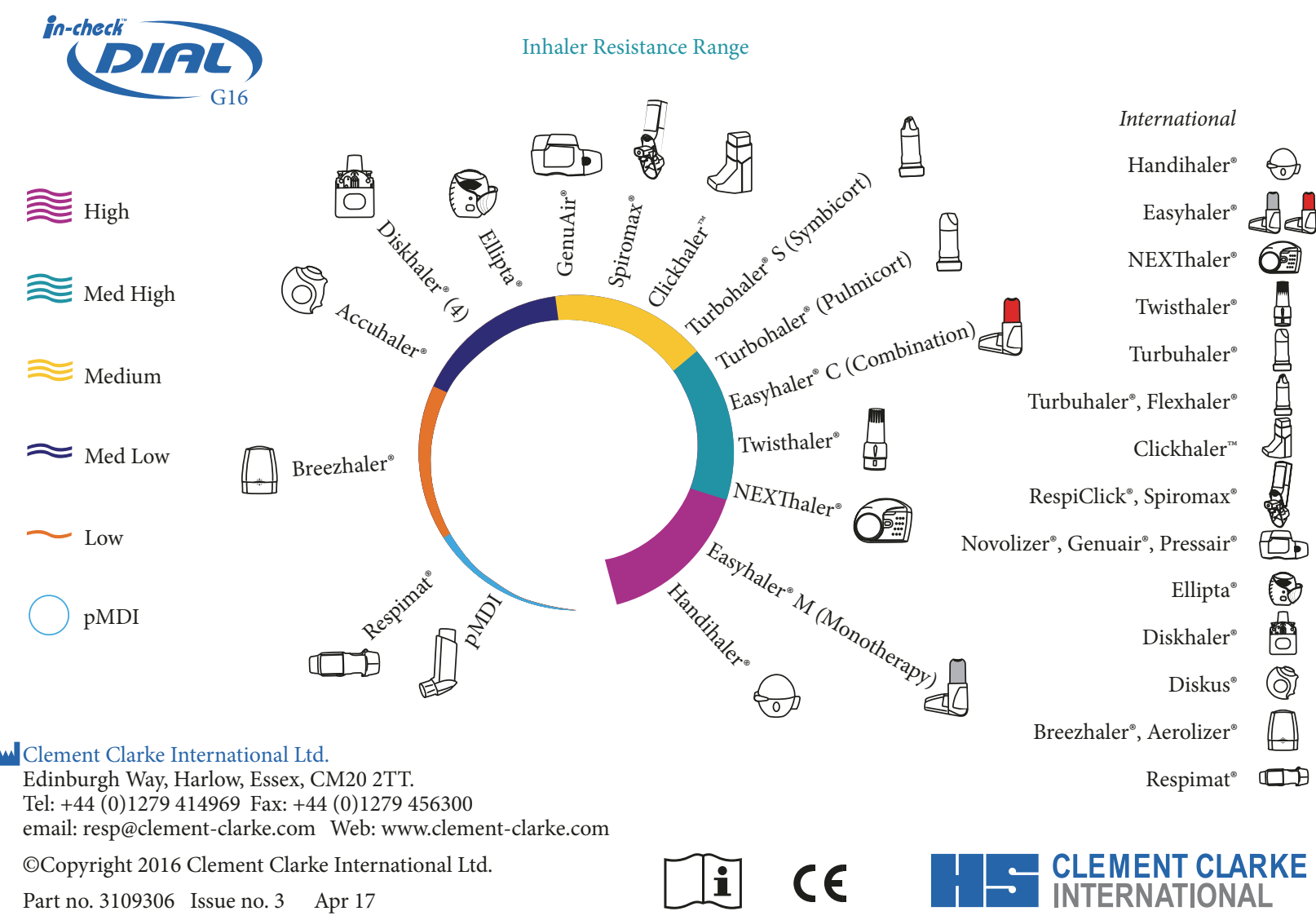

FIgURE 2: In-Check DIAL G16 Information Card. 
TABLE 3: Use scenarios and maintenance of the In-Check DIAL G16.

\begin{tabular}{|c|c|}
\hline \multicolumn{2}{|c|}{ In-Check DIAL G16 } \\
\hline Use scenarios & In-Check maintenance and components \\
\hline $\begin{array}{l}\text { To comply with Guidelines that require inhaler technique } \\
\text { training to be conducted } \\
\text { To provide objective inhaler technique/flow rate data } \\
\text { To assess whether poorly-controlled patients have adequate } \\
\text { inhaler technique } \\
\text { To conduct training in the absence of specific } \\
\text { trainer/demonstrator devices } \\
\text { To guide/tailor inhaler device selection } \\
\text { To support trainer-related reimbursement }\end{array}$ & $\begin{array}{l}\text { See Instructions for Use for details: } \\
\text { (i) Wash in warm mild detergent solution for a maximum of } 5 \text { minutes. } \\
\text { Agitate the water } \\
\text { (ii) Rinse in warm water and shake to remove any excess water by } \\
\text { holding at the end furthest away from the DIAL } \\
\text { (iii) Allow to dry thoroughly before reuse } \\
\text { Additional components: } \\
\text { (i) Disposable mouthpieces } \\
\text { (ii) Filtered mouthpieces } \\
\text { (iii) Restriction adaptors for specific DPI resistance requirements }\end{array}$ \\
\hline
\end{tabular}

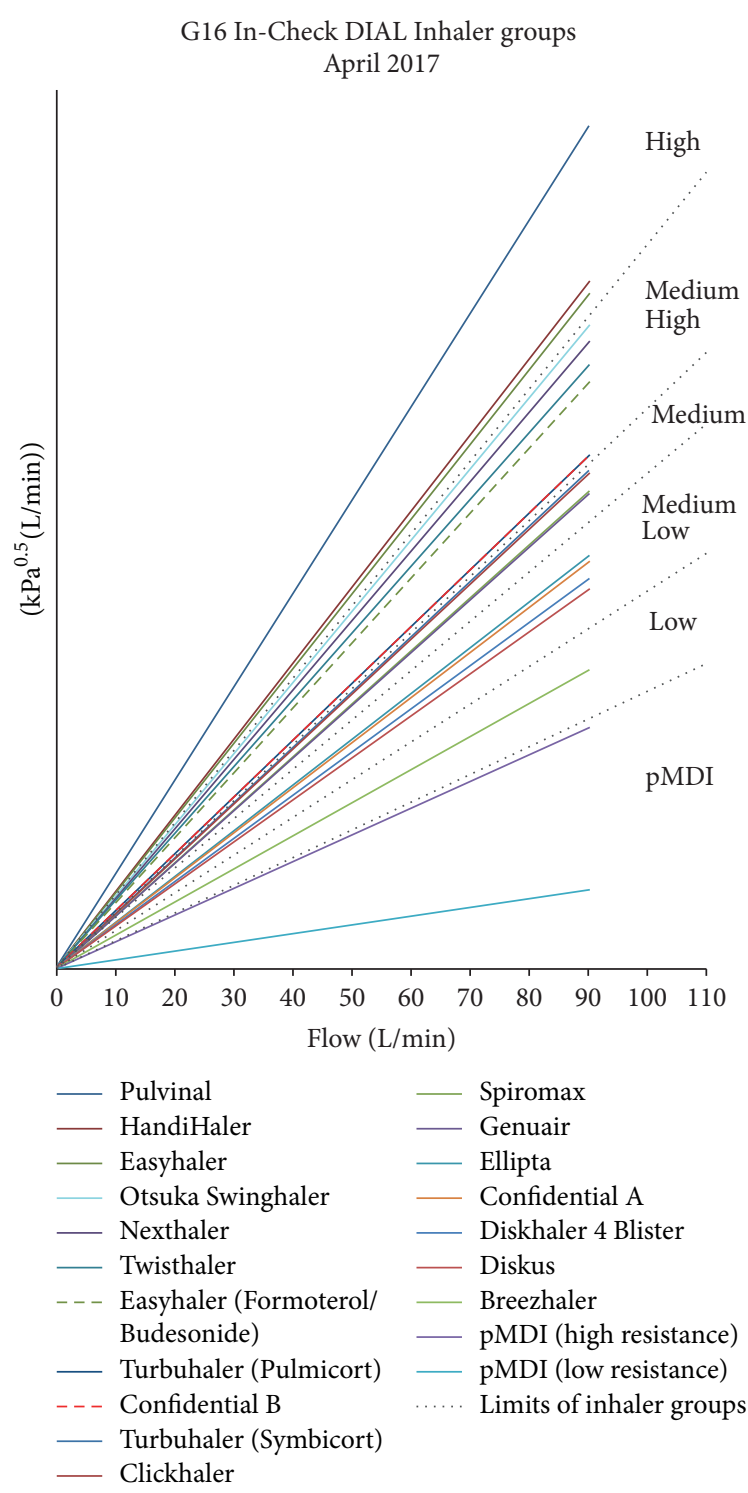

FIGURE 3: In-Check DIAL G16 ranges of device resistance.

\section{Discussion}

In-Check DIAL has been widely used in asthma clinics since the early 2000s. The data from the Isle of Wight study $[10,37,38]$ demonstrate the value of institutional and home-use training aids: pharmacists were initially instructed on how to use the inhalers themselves and then trained to measure a patient's ability to use the prescribed inhaler using the In-Check DIAL. The entirety of the project delivered a reduction of $>50 \%$ in emergency admissions and a fall in asthma-associated deaths of $75 \%$, alongside reduced shortacting bronchodilator use. This research provided remarkable, clinically quantifiable improvements in patient wellbeing. The daily use scenarios to which the In-Check DIAL can be put (Table 3) are directly supportive to this type of medicines use review [37].

In-Check DIAL can also be used in the assessment of treatment options for chronic obstructive pulmonary disease (COPD) patients [18]. COPD may be characterised during exacerbations by a suboptimal peak inspiratory flow [22] that would affect a patient's ability to receive medication effectively and has been shown to be independently predictive of hospital COPD readmissions [39]. New research with the G16 is being directed to coaching COPD patients to improve their peak inspiratory flow and to determine if its measurement can help personalise inhaler selection [18].

\section{Conclusion}

Training that can be delivered swiftly, establishing good inhaler technique alongside understanding, may free-up time during consultation sessions to address adherence explanations. The ultimate aim is to establish individual asthma management plans built upon good inhaler competency and good adherence.

\section{Conflicts of Interest}

The author is the Managing Director of Clement Clarke International Limited.

\section{Acknowledgments}

The following trademarks are acknowledged: Autohaler (3M Company); Breezhaler (Novartis AG); Clickhaler (Tianjin Kinnovata Pharmaceutical Company Limited); Diskhaler, Diskus and Ellipta (Glaxo Group Limited); Easi-breathe 
(Norton Healthcare Limited); Easyhaler (Orion Corporation); Flexhaler (AstraZeneca AB); Flo-Tone (Clement Clarke International Limited); Genuair (AstraZeneca AB); HandiHaler (Boehringer Ingelheim Pharma GmbH \& Co. KG); In-Check DIAL (Clement Clarke International Limited); Neohaler (Novartis AG); Nexthaler (Chiesi Farmaceutici s.p.a.); Novolizer, Pressair and Pulmicort (AstraZeneca AB); Pulvinal (Chiesi Farmaceutici s.p.a); Respiclick (IVAX International B.V./Teva Respiratory, LLC); Respimat (Boehringer Ingelheim Pharma GmbH \& Co. KG); Spiromax (IVAX International B.V.); Swinghaler (Otsuka Pharamceutical Co., Ltd); Symbicort and Turbuhaler (AstraZeneca AB); Twisthaler (MSD International Holdings $\mathrm{GmbH}$ ).

\section{References}

[1] J. Sanchis, C. Corrigan, M. L. Levy, and J. L. Viejo, "Inhaler devices-From theory to practice," Respiratory Medicine, vol. 107, no. 4, pp. 495-502, 2013.

[2] H. Chrystyn, J. Van Der Palen, R. Sharma et al., "Device errors in asthma and COPD: Systematic literature review and metaanalysis," npj Primary Care Respiratory Medicine, vol. 27, no. 1, article no. 22, 2017.

[3] B. L. Laube, H. M. Janssens, F. H. C. De Jongh et al., "What the pulmonary specialist should know about the new inhalation therapies," European Respiratory Journal, vol. 37, no. 6, pp. 13081331, 2011.

[4] Global Initiative for Asthma, "2017 GINA Report, Global Strategy for Asthma Management and Prevention," Global Initiative for Asthma, 2017, http://ginasthma.org/2017-gina-reportglobal-strategy-for-asthma-management-and-prevention/.

[5] British Thoracic Society Scottish Intercollegiate Guidelines Network, "British guideline on the management of asthma," Thorax, vol. 63, Supplement 4, pp. iv1-iv121, 2008.

[6] National Guideline Centre, "Asthma management. Asthma: The management of asthma. Draft for consultation," 2016, Publ. National Guideline Centre, https://www.nice.org.uk/guidance/ gid-cgwave0743/documents/full-guideline-updated, Expected publication date of "The chronic asthma management guideline”, 2017, https://www.nice.org.uk/guidance/indevelopment/ gid-cgwave0743.

[7] National Heart, Lung, and Blood Institute (NHLBI), "National Asthma Education and Prevention Program. Expert Panel Report 3: Guidelines for the diagnosis and management of asthma," NIH Publication No. 07-4051, 2007, https://www.nhlbi .nih.gov/health-pro/guidelines/current/asthma-guidelines/fullreport.

[8] M. Ichinose, H. Sugiura, H. Nagase et al., "Japanese guidelines for adult asthma 2017," Allergology International, vol. 66, no. 2, pp. 163-189, 2017.

[9] E. Azzi, P. Srour, C. Armour, C. Rand, and S. Bosnic-Anticevich, "Practice makes perfect: self-reported adherence a positive marker of inhaler technique maintenance," npj Primary Care Respiratory Medicine, vol. 27, article no. 29, 2017.

[10] Isle of Wight PCT, "Shared learning database: Isle of Wight PCT," National Institute for Health and Care Excellence, February 2011, https://www.nice.org.uk/sharedlearning/isle-ofwight-respiratory-inhaler-project.

[11] K. B. Saunders, "Bronchodilator response patterns in patients with chronic airways obstruction: use of peak inspiratory flow rate," British Medical Journal, vol. 2, no. 5549, pp. 399-402, 1967.
[12] B. M. Wright, "A miniature Wright peak-flow meter," British Medical Journal, vol. 2, no. 6152, pp. 1627-1628, 1978.

[13] L. J. F. Youlten, “The peak nasal inspiratory flow meter: a new instrument for the assessment of the response to immunotherapy in seasonal allergic rhinitis," Allergologia et Immunopathologia, vol. 8, pp. 344-347, 1980.

[14] M. H. Depledge, "Peak inspiratory flow: Measurement using a modified mini Wright peak flow meter," Thorax, vol. 40, no. 3 , pp. 205-206, 1985.

[15] T. G. D. Capstick and I. J. Clifton, "Inhaler technique and training in people with chronic obstructive pulmonary disease and asthma," Expert Review of Respiratory Medicine, vol. 6, no. 1, pp. 91-103, 2012.

[16] J. van der Palen, "Peak inspiratory flow through Diskus and Turbuhaler, measured by means of a peak inspiratory flow meter (In-Check DIAL ${ }^{\circledR}$ ), Respiratory Medicine, vol. 97, no. 3, pp. 285-289, 2003.

[17] H. Chrystyn, "Is inhalation rate important for a dry powder inhaler? Using the In-Check Dial to identify these rates," Respiratory Medicine, vol. 97, no. 2, pp. 181-187, 2003.

[18] D. A. Mahler, "Peak inspiratory flow rate as a criterion for dry powder inhaler use in chronic obstructive pulmonary disease," Annals of the American Thoracic Society, 2017.

[19] A. R. Clark and A. M. Hollingworth, "The relationship between powder inhaler resistance and peak inspiratory conditions in healthy volunteers - implications for in vitro testing," Journal of Aerosol Medicine: Deposition, Clearance, and Effects in the Lung, vol. 6, no. 2, pp. 99-110, 1993.

[20] ISO 23747:2015, "Anaesthetic and respiratory equipment peak expiratory flow meters for the assessment of pulmonary function in spontaneously breathing humans," International Organization for Standardization, Edition 2, pp 1-26, August 2015, https://www.iso.org/standard/64926.html.

[21] S. Pedersen, O. R. Hansen, and G. Fuglsang, "Influence of inspiratory flow rate upon the effect of a Turbuhaler," Archives of Disease in Childhood, vol. 65, no. 3, pp. 308-310, 1990.

[22] R. A. M. Al-Showair, W. Y. Tarsin, K. H. Assi, S. B. Pearson, and H. Chrystyn, "Can all patients with COPD use the correct inhalation flow with all inhalers and does training help?" Respiratory Medicine, vol. 101, no. 11, pp. 2395-2401, 2007.

[23] K. Berkenfeld, A. Lamprecht, and J. T. McConville, "Devices for dry powder drug delivery to the lung," AAPS PharmSciTech, vol. 16, no. 3, pp. 479-490, 2015.

[24] J. Dederichs, D. Singh, and R. Pavkov, "Inspiratory flow profiles generated by patients with COPD through the Breezhaler ${ }^{\circledR}$ inhaler and other marketed dry powder inhalers," American Journal of Respiratory and Critical Care Medicine, vol. 191, Abstract A5793, 2015.

[25] G. W. Canonica, J. Arp, J. R. Keegstra, and H. Chrystyn, "Spiromax, a new dry powder inhaler: dose consistency under simulated real-world conditions," Journal of Aerosol Medicine and Pulmonary Drug Delivery, vol. 28, no. 5, pp. 309-319, 2015.

[26] S. I. Yakubu, K. H. Assi, and H. Chrystyn, "Aerodynamic dose emission characteristics of dry powder inhalers using an Andersen Cascade Impactor with a mixing inlet: The influence of flow and volume," International Journal of Pharmaceutics, vol. 455, no. 1-2, pp. 213-218, 2013.

[27] H. W. Frijlink and A. H. De Boer, "Dry powder inhalers for pulmonary drug delivery," Expert Opinion on Drug Delivery, vol. 1, no. 1, pp. 67-86, 2004. 
[28] A. J. Lexmond, T. J. Kruizinga, P. Hagedoorn, B. L. Rottier, H. W. Frijlink, and A. H. De Boer, "Effect of inhaler design variables on paediatric use of dry powder inhalers," PLoS ONE, vol. 9, Article ID e99304, 2014.

[29] P. Krüger, B. Ehrlein, M. Zier, and R. Greguletz, "Inspiratory flow resistance of marketed dry powder inhalers (DPI)," European Respiratory Journal, vol. 44, suppl. no. 58, abstract no. 4635, 2014.

[30] S. Hoe, D. Traini, H.-K. Chan, and P. M. Young, "Measuring charge and mass distributions in dry powder inhalers using the electrical Next Generation Impactor (eNGI)," European Journal of Pharmaceutical Sciences, vol. 38, no. 2, pp. 88-94, 2009.

[31] S. Hoe, D. Traini, H.-K. Chan, and P. M. Young, "The influence of flow rate on the aerosol deposition profile and electrostatic charge of single and combination metered dose inhalers," Pharmaceutical Research, vol. 26, no. 12, pp. 2639-2646, 2009.

[32] P. Haidl, S. Heindl, K. Siemon, M. Bernacka, and R. M. Cloes, "Inhalation device requirements for patients' inhalation maneuvers," Respiratory Medicine, vol. 118, pp. 65-75, 2016.

[33] F. Buttini, G. Brambilla, D. Copelli et al., "Effect of flow rate on in vitro aerodynamic performance of Nexthaler ${ }^{\circledR}$ in comparison with Diskus ${ }^{\circledR}$ and Turbohaler ${ }^{\circledR}$ dry powder inhalers," Journal of Aerosol Medicine and Pulmonary Drug Delivery, vol. 29, no. 2, pp. 167-178, 2016.

[34] M. Scuri, V. Alfieri, A. Giogio et al., "Measurement of the inhalation profile through a novel dry powder inhaler (Nexthaler) in asthmatic patients using acoustic monitoring," American Journal of Respiratory and Critical Care Medicine, vol. 187, p. A1931, 2013.

[35] R. W. Dal Negro, "Dry powder inhalers and the right things to remember: A concept review," Multidisciplinary Respiratory Medicine, vol. 10, article no. 13, 2015.

[36] S. Luik, "Spiriva Respimat (tiotropium bromide) inhalation spray (presentation), United States Food and Drug Administration Pulmonary-Allergy Drugs Advisory Committee, 14 August 2014," https://www.pdffiller.com/en/project/144097789 .$h t m ? f$ hash $=f f 766 \mathrm{~d} \&$ reload=true.

[37] J. Portlock, M. Holden, and S. Patel, "A community pharmacy asthma MUR project in Hampshire and the Isle of Wight," The Pharmaceutical Journal, vol. 282, no. 7537, pp. 109-112, 2009.

[38] News, "Early data from Isle of Wight MURs indicate drop in asthma deaths," The Pharmaceutical Journal, vol. 282, p. 99, 2009.

[39] C. Loh, T. M. Lovings, and J. A. Ohar, "Low inspiratory flow rates predict COPD and all cause readmissions," American Journal of Respiratory and Critical Care Medicine, vol. 193, Abstract A1125, 2016. 


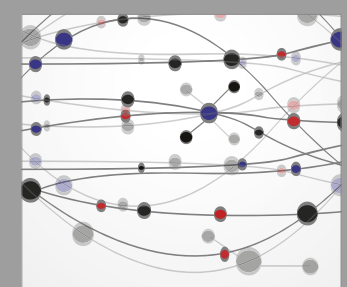

The Scientific World Journal
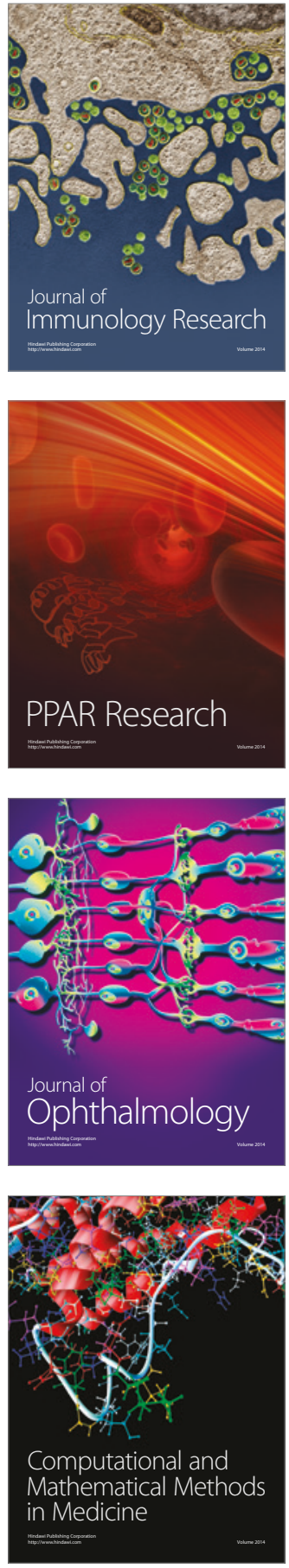

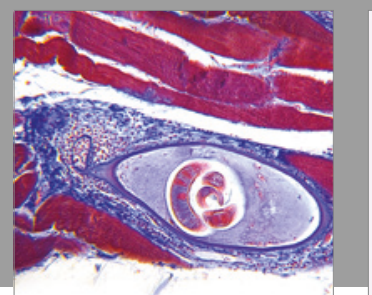

Gastroenterology Research and Practice
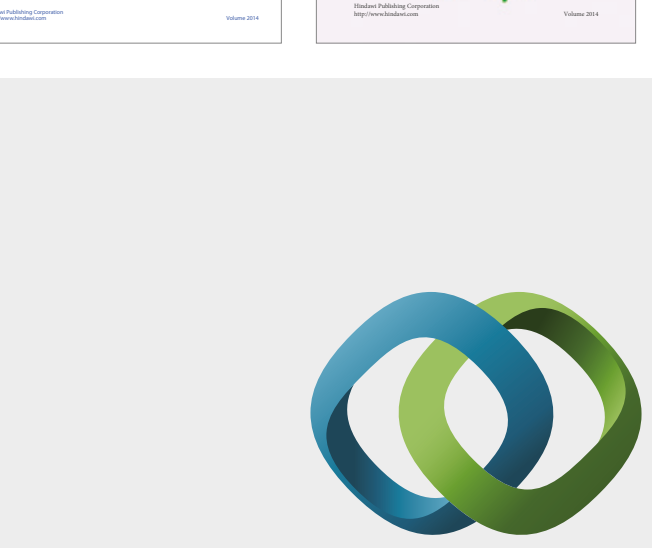

\section{Hindawi}

Submit your manuscripts at

https://www.hindawi.com
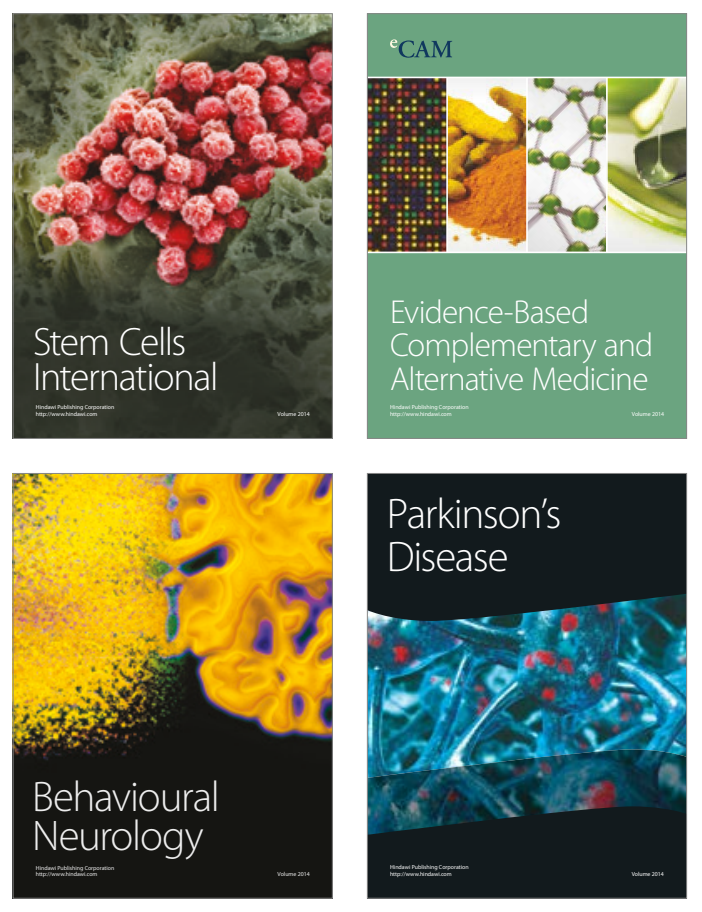
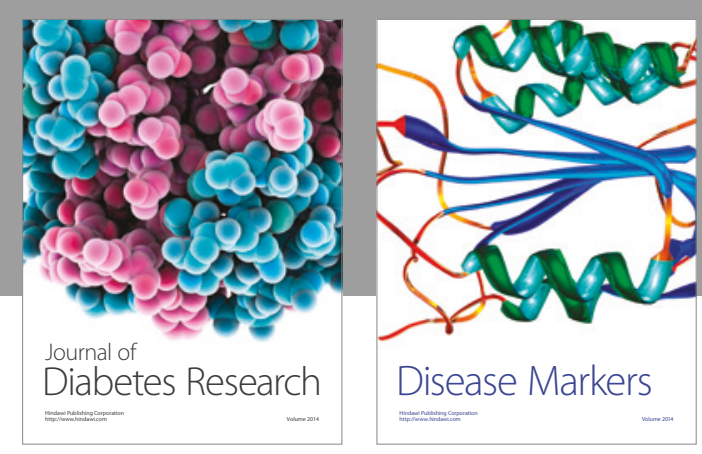

Disease Markers
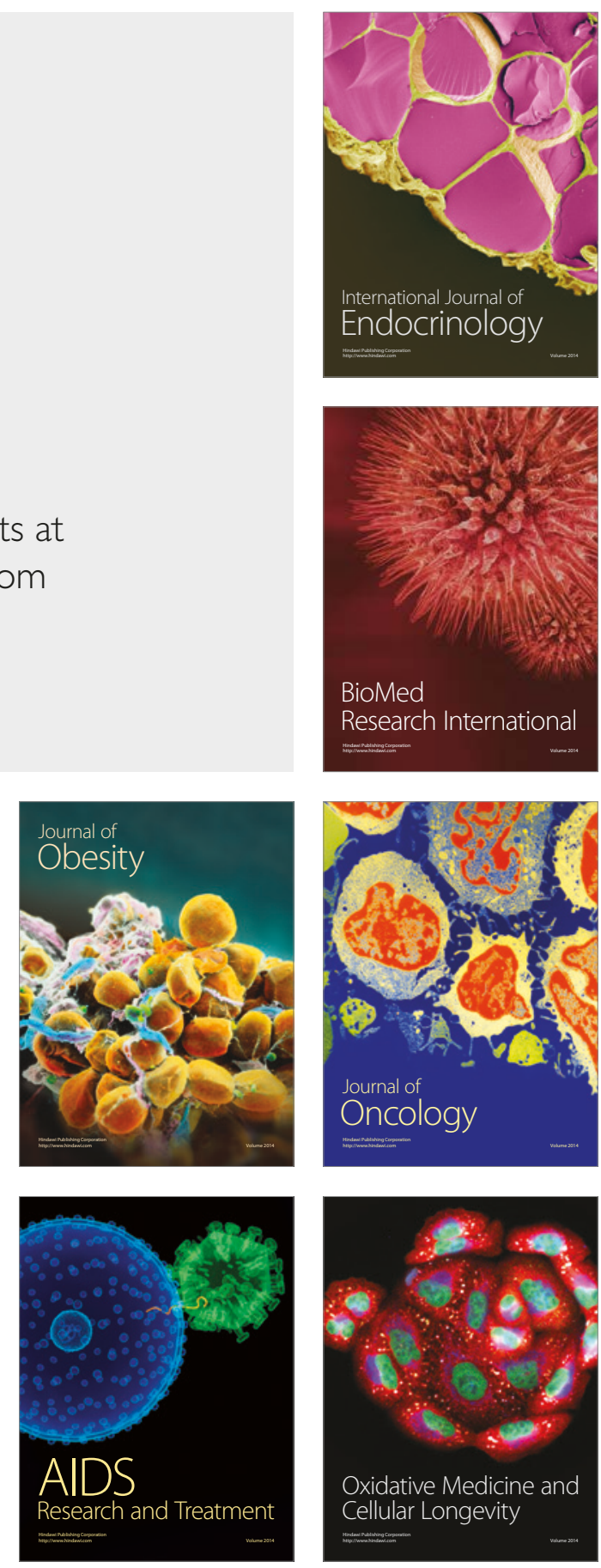